\title{
FORMAS SIMBÓLICAS ESPACIAIS PRESENTES NA IGREJA UNIVERSAL DO REINO DE DEUS
}

\author{
Christovam Reis dos Santos Filho ${ }^{1}$
}

\section{Resumo:}

O artigo propõe uma interpretação de um espaço sagrado representado pela Igreja Universal do Reino de Deus - Templo Central de Fortaleza (IURD-TCF), a partir do conceito de formas simbólicas espaciais. O texto se insere na seara dos estudos da Geografia da Religião, enfocando os significados vividos espacialmente, tendo por análise os símbolos em um espaço sagrado, por meio das formas simbólicas espaciais. Objetivamos compreender, portanto, as formas simbólicas espaciais existentes no espaço sagrado organizado pela IURDTCF. De maneira específica, buscamos entender a importância dos símbolos para relação entre espaço e religião; apreender o que são as formas simbólicas espaciais e; identificar elementos que fazem da IURD-TCF uma forma simbólica espacial. Nossa metodologia se pauta numa investigação bibliográfica, além de um trabalho investigativo a partir do olhar sobre o real. Com isso, consideramos que IURD-TCF é uma forma simbólica espacial, na qual a sacralidade é vivida pela percepção dos frequentadores por meio da significação dada às formas do templo durante sua vivência no espaço.

Palavras-chave: Espaço sagrado; Forma simbólica espacial; Igreja Universal do Reino de Deus.

\begin{abstract}
:
The paper proposer na interpretation of a sacred space represented by Igreja Universal do Reino de Deus - Fortaleza's Central Temple (IURD - FCT), from the concept of space symbolic forms. The text is included in a harvest of the religion geography studies, focusing the meanings lived sapatially, having symbols of a sacred space by analysis, through the spatial symbolic forms. We aim to understand, therefore, the spatial symbolic forms that there is at a sacred space organized by IURD - FCT. In a specific way, we seek understand the importance of symbols to the relation between the space and religion; to realize what is the spatial symbolic forms and; to indentify the elements that makes IURD - FCT as a spatial symbolic forms. Our methodology is guided in a bibliography research, as well as investigative work from the look of researcher on the real object. Thereat, we consider IURD - FCT as a spatial symbolic form, in which the sacredness is lived by perception of the goers through the meanings given to the temple forms during his experience in space.
\end{abstract}

Key-words: Sacred space; Spatial Symbolic Form; Igreja Universal do Reino de Deus.

\footnotetext{
${ }^{1}$ Mestre em Geografia pela Universidade Estadual do Ceará (UECE) e professor da rede estadual de ensino do Ceará. E-mail: santosfilho20@gmail.com
} 


\section{Introdução}

Pretendemos neste artigo uma interpretação de um espaço sagrado representado pela Igreja Universal do Reino de Deus - Templo Central de Fortaleza (IURD-TCF). Para isso, entendemos a igreja como um conjunto de símbolos espacializados mediante a relação entre os frequentadores e o seu espaço vivido. Esta relação ocorre pela percepção das pessoas por meio de suas experiências com o lugar. Dessas experiências, são construídos novos significados que valorizam e direcionam uma identidade com o local, moldando suas práticas espaciais e culturais. As formas apresentadas pelo templo são elementos condicionantes dessa experiência, uma vez que os geossímbolos ali envolvidos fornecem significados percebidos e vivenciados pelos frequentadores desta igreja.

Esta pesquisa se insere nos estudos da Geografia da Religião, na qual tem entre suas opções metodológicas a dimensão simbólica e a valorização do significado para a compreensão das vivências do cotidiano em espaços sagrados. Estas são compartilhadas por pessoas e mediadas por símbolos que se comunicam e constroem novos significados para os objetos, criando assim um espaço vivido. Dentre os aspectos culturais vivenciados temos a religião, que se fundamenta na vivência do sagrado.

Logo, objetivamos compreender as formas simbólicas espaciais existentes no espaço sagrado organizado pela IURD-TCF. Para isto, entendemos a importância dos símbolos para relação entre espaço e religião; apreendemos as formas simbólicas espaciais e; identificar elementos que fazem da IURD-TCF uma forma simbólica espacial.

Este templo se localiza na Avenida Tristão Gonçalves, 613, no centro de Fortaleza, Ceará (Figura 1). A infraestrutura da igreja compõe-se de nave com capacidade para 3000 pessoas sentadas ${ }^{2}$; um prédio/alojamento, onde se instalam os pastores missionários e locais para reuniões eclesiásticas; um prédio anexo onde os pastores fazem sua concentração e logística dos cultos; estacionamentos, um subterrâneo e outro localizado em frente à entrada principal do templo; além de instalações para recepção, fraldário, banheiros e; locais para atendimento ao público na entrada secundária situada à rua paralela ao endereço oficial do templo.

\section{Figura 1 - Fachada principal da IURD-TCF.}

\footnotetext{
2 Segundo informações da construtora responsável. Fonte: FUJITA Engenharia. Disponível em: <http://novo.fujita.com.br/projetos/obras-institucionais/>. Acesso em: 15/02/2016. Já na porta do templo há um cartaz informando ser a capacidade para 3500 pessoas.
} 


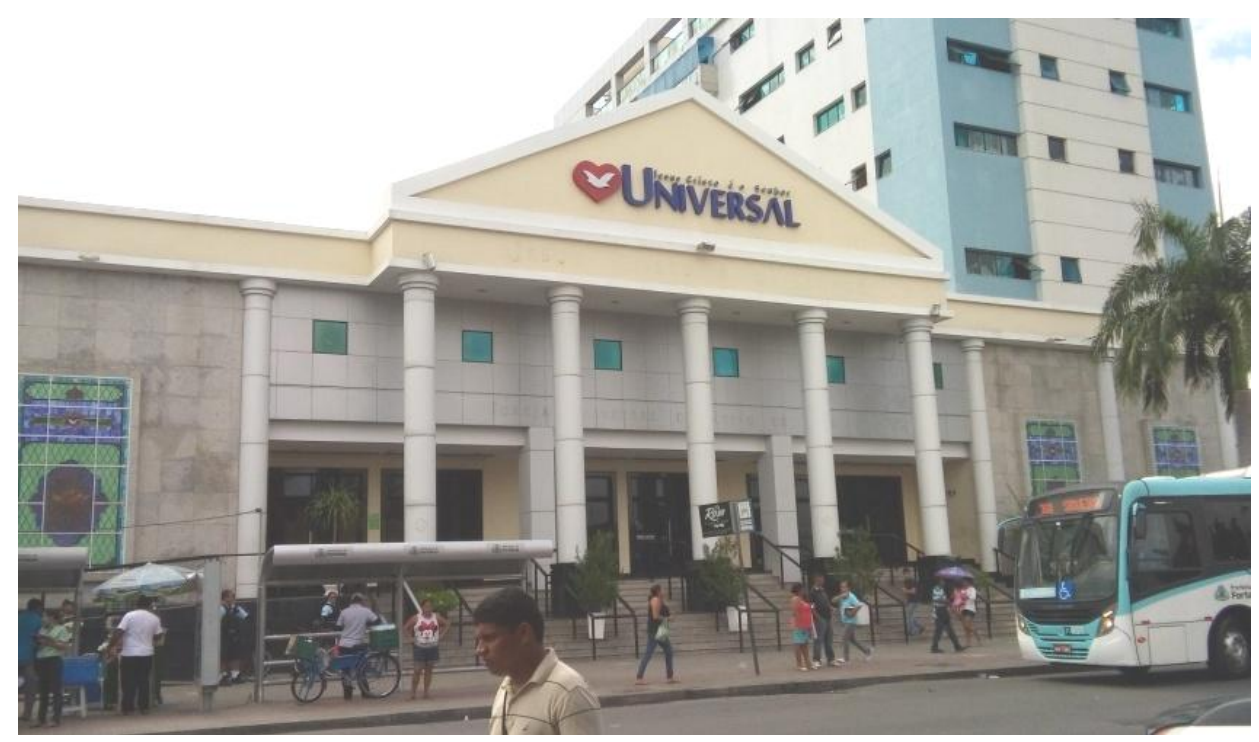

Fonte: Autor, 2016.

Este templo é uma sede estadual da Igreja Universal do Reino de Deus (IURD) responsável pela administração da instituição no Ceará, além dos estados de Piauí e Maranhão. No Ceará a IURD conta com 316 templos $^{3}$, sendo a IURD-TCF o maior e também responsável pelo remanejamento de pastores nas demais sedes cearenses, além de distribuir materiais elaborados pela igreja, como as edições do jornal Folha Universal. É visível para os membros da igreja que o templo central de Fortaleza é uma centralidade espacial, representada pela grandiosidade de seu monumento, que abrange suas formas simbólicas espaciais.

Nossa metodologia baseia-se em estudos bibliográficos dos conceitos pertinentes à presente análise. Consideramos as abordagens teóricas que discutem o conceito de símbolo e formas simbólicas espaciais, além de buscarmos uma fundamentação associadas aos conceitos de sagrado e profano. Na seara geográfica, atentamos aos conceitos de espaço e espaço sagrado. A dimensão empírica envolve a prospecção sobre dados da IURD na qual usamos como objeto de estudo e realizamos observações de campo para averiguar as informações obtidas ou não suficientes através de dados sobre o local.

\footnotetext{
3 Website (Wordpress) da IURD. Disponível em: <https://iurdenderecos.wordpress.com/about/br-ceara/>. Acesso em: 04/07/16.
} 


\title{
Fundamentação teórica
}

O sagrado é o elemento presente na vida humana e a partir do momento em que ele se manifesta espacialmente. Quando isto ocorre, temos um espaço sagrado, que segundo Eliade (1979) é oposto ao espaço profano, a partir da presença de uma hierofania. Rosendahl afirma que "o espaço sagrado é o lócus de uma hierofania, isto é, uma manifestação do sagrado" (ROSENDAHL, 2006, p. 121). Assim, há uma relação entre o sujeito e espaço sagrado, criando um ambiente diferente do que se vive no cotidiano.

Essa espacialidade é confirmada por meio de ritos que são ciclicamente repetidos rememorando a sacralidade do lugar. Podemos dizer que

\begin{abstract}
Um objeto ou uma ação só se tornam reais na medida em que imitam ou repelem um arquétipo. Assim, a realidade só é atingida pela repetição ou pela participação; tudo o que não possui um modelo exemplar é 'desprovido de sentido', isto é, não possui realidade. Esta tendência pode parecer paradoxal, no sentido de que o homem das culturas tradicionais só se reconhece como real na medida em que deixa de ser ele próprio (para um observador moderno) e se contenta em imitar e repetir os gestos de um outro. (ELIADE, 1985, p. 49, grifos do autor).
\end{abstract}

Desse modo, podemos inserir a IURD-TCF como um espaço sagrado, pois os rituais ciclicamente repetidos em seu templo fazem deste local distinto dos profanos, isto é, fora dos templos. Assim, este templo é resultante de um processo por meio das funções e significados gerado pela forma simbólica espacial que ele representa.

Destacamos o espaço geográfico resultante da percepção que as formas da paisagem transmitem ao observador. Segundo Costa (2013, p. 150) "a leitura da paisagem a partir do símbolo, torna-se uma empresa da Geografia Humanística, que discute categorias tais como paisagem e lugar como e que se torna familiar ao indivíduo.”. Oferecendo esteio ao estudo geográfico humanista, a paisagem é interpretada mediante os símbolos percebidos pelos sujeitos que a vivenciam.

Pressuposto que o corpo é o agente de conexão entre o consciente e o mundo, ou seja, é o elemento essencial da percepção. Desta forma, concordamos ser o corpo uma relação entre o ser e o espaço. Para referendar a afirmativa anterior, consideramos os estudos de MerleauPonty (1908-1961) que trabalha o corpo a partir do entendimento da fenomenologia da percepção. $\mathrm{O}$ autor entende a compreensão da realidade como fruto de uma relação entre o ser com o mundo mediado pelo corpo. É através da consciência perceptiva que o sujeito irá se deparar com algo que se apresenta diante de sua consciência. Assim, o constructo teórico de Merleau-Ponty parte da compreensão de que o corpo é a ponte entre o ser e o espaço. 
A percepção faz parte da experiência, enquanto ligação entre o sujeito e o mundo, para a formação dos símbolos. Nas palavras de Rocha (2013, p. 75), "a percepção é a forma como, através dos sentidos, as coisas do mundo natural ou humano chegam à consciência". Isso somente ocorre porque "o homem está no mundo, é no mundo que ele se conhece" (MERLEAU-PONTY, 2011, p. 8). Ou seja, é uma relação espacial, mediada pela relação corpo e mundo.

Mediante a isto, recorremos à definição de que "Perceber é envolver em um só golpe todo um futuro de experiências em um presente que a rigor nunca o garante, é crer em um mundo." (MERLEAU-PONTY, 2011, p. 399). O autor continua afirmando que "perceber é [...] apreender um sentido imanente ao sensível antes de qualquer juízo”. (Op. cit. p. 63). Assim perceber é uma junção entre experiência e a projeção simultânea dos objetos sensíveis, de modo que estes objetos são assimilados inseparavelmente à sua essência. A experiência é o elemento geográfico existente na relação espaço e símbolo.

O símbolo etimologicamente se refere "a reunir duas partes separadas" (RUIZ, 2004, p. 133). Segundo este autor, “o símbolo tem como potencialidade própria a conjunção das partes fraturadas numa nova unidade significativa" (RUIZ, 2004, p. 134, grifo do autor). Ou seja, as partes são coisas que antes, separadas, não remetiam a um significado comum, porém pela experiência do sujeito adquirem signos que se complementam em algo novo, um novo significado, que faz parte do vivido pelo sujeito. Podemos dizer que "o símbolo é um signo que tem uma relação de convenção com seu objeto." (ROCHA, 2013, p. 74). Deste modo, os símbolos são construídos convencionalmente, dotados de uma pluralidade de significados cujos objetos, a priori, não se destinavam a significar.

Segundo a classificação de Pierce, na interpretação de Santaella (1990), o símbolo é de lei, isto é, uma adoção de significado universal, determinada socialmente. Em outras palavras, o símbolo

Extrai seu poder de representação porque é portador de uma lei que, por convenção ou pacto coletivo, determina que aquele signo represente seu objeto. [...] Desse modo, o objeto de uma palavra não é a alguma coisa existente, mas uma ideia abstrata, lei armazenada na programação linguística de nossos cérebros. (SANTAELLA, 1990, p. 67).

Podemos também definir o símbolo como uma projeção humana sobre um objeto. Em outras palavras, 
Tudo o que, da parte do homem, coporta além de sua significação imediata um segundo sentido, que transfigura a realidade material e garante assim uma mediação entre o cotidiano do homem de onde provém este sinal e uma realidade que o ultrapassa. (MESLIN, 1992, p. 168).

O símbolo vai além da interpretação inicial, pois são acrescidos de significados cujos contextos espaço-temporais são os mais diversos. Implica-se, portanto, a uma polivocalidade, “isto é, as múltiplas construções de significados.” (CORRÊA, 2011, p. 13). Assim, o símbolo expressa diferentes interpretações numa mesma paisagem, cabendo ao sujeito a sua maneira de atribuir um significado por meio da vivência.

Esses símbolos são ligações entre o sujeito e o objeto. Pela vivência o sujeito se encontra no espaço mediado pelos símbolos que suas relações oferecem. Isto é, "Essa relação entre o indivíduo e a paisagem é, portanto, mediatizada por uma rede simbólica cuja materialidade traz também o imaterial, algo visível que mostra o invisível, um gesto que significa um valor.” (COSTA, 2013, p. 151). O que é visível, através das formas na paisagem exibe, de maneira perceptiva, o que também não está nas formas, mas sim nas relações espaciais, uma vez que o espaço abrange também a vida que o anima (SANTOS, 1988).

O símbolo, então, se manifesta no espaço mediante das formas visíveis, de maneira subjetiva por meio de relações cotidianas estabelecidas pelos sujeitos. No caso do nosso estudo, o templo é a forma visível espacialmente, que transmite símbolos que são vividos pelos frequentadores ao passarem ou o adentrarem. Desta forma, os signos existentes no templo remetem a uma simbologia específica, nos quais direcionam o olhar dos frequentadores de modo que o sagrado é apresentado espacialmente pela paisagem refletida nos signos.

A experiência vivida pela percepção traz ao sujeito uma forma particular de interpretar aquele lugar e justificar suas ações e maneira de viver. Por isto, temos neste espaço uma vivência. Ou seja, "O espaço é vivido e percebido de maneira diferente pelos indivíduos" (LENCIONI, 2003, p. 152). O vivido é particular do que cada um interpreta dos símbolos ali existentes, isto é, "o espaço vivido passa a ser construído socialmente através da percepção e da interpretação dos indivíduos, revelando as práticas sociais." (PEREIRA; CORREIA; OLIVEIRA, 2010, p. 176).

A interpretação do espaço sagrado perpassa, então, o significado simbólico da paisagem. Os elementos presentes na paisagem são assimilados perceptivamente e 
interpretados a partir dos símbolos captados pelos sujeitos, o que justifica suas ações e fornecem uma explicação da realidade.

Quando esses símbolos estão geograficamente delimitados podemos dizer que são geossímbolos. Tomamos nossa compreensão de geossímbolo a partir da definição proposta por Joël Bonnemaison, quando ele afirma que

um geossímbolo pode ser definido como um lugar, um itinerário, uma extensão que, por razões religiosas, políticas ou culturais, aos olhos de certas pessoas e grupos étnicos assume uma dimensão simbólica que os fortalece em sua identidade. (BONNEMAISON, 2002, p. 109)

Os geossímbolos possuem um poder identitário que promovem aos sujeitos a ação de vivenciar um lugar. "Essas representações simbólicas revestem-se de um poder que gera um interacionismo entre as formas espaciais e o sujeito" (COSTA, 2009, p. 49). O sujeito vivencia e modifica o espaço pelas interações simbólicas com o lugar.

Estas interações são vividas no momento em que os sujeitos estabelecem demarcações, físicas ou não com o lugar, gerando uma diferenciação entre lugares. Onde se vive se cria laços e estes são demarcados simbolicamente, ou também fisicamente, no espaço pelo território. Neste ponto, concordamos com Bonnemaison (1992) quando diz que o território é um espaço simbólico, pois é atrelado aos sentidos e à memória dos sujeitos. Quando as relações espaciais são demarcadas simbolicamente exprimem um sentimento não somente de vivência, mas de potência em relação ao lugar, uma vez que o sujeito se sente participante e capaz de atuar naquele local, criando uma identidade. Deste modo, ele associa os sentimentos (crenças e desejos) sentidos naquele espaço por meio de símbolos, construídos ao interagir com o lugar.

No caso de um templo religioso, os geossímbolos possibilitam um contato frequente entre o humano e o divino. Se tomarmos como exemplo a IURD-TCF, percebemos que o próprio templo é um geossímbolo, por razão religiosa, marcado por uma dimensão simbólica no qual se refere à identidade do grupo que o frequenta. Isto porque quem convive se identifica no lugar como pertencente aos que podem entrar em contato com o divino. Entretanto, quem apenas passa pela frente do templo, quem o vê por fora, também identifica naquela construção um lugar de predominância religiosa, mas não pertencente a sua crença particular. Neste caso, mesmo sendo de entendimento doutrinário distinto, ela reconhece no 
templo um local onde ocorre o contato com o divino, em alguns casos, convidando a pessoas de outras crenças a visitarem e constatarem como a religiosidade ali se pratica.

Portanto, os geossímbolos são pontos ou trajetórias nos quais há um direcionamento simbólico. Ou seja, é "algo material ou imaterial que ali está para nos remeter a outro ponto, reificar uma ideia ou lugar diverso.” (CORRÊA, 2006, p. 53). No nosso objeto de estudo, o símbolo remete ao centro do mundo (ELIADE, 1979), ao local onde Deus certamente se faz presente a quem o busca. Como estes símbolos estão espacialmente delimitados, podemos dizer que são as formas apreendidas na relação entre sujeito e objeto que ressignificam o lugar. Como se trata de delimitações de razões religiosas, as formas contextualizam símbolos sagrados, cujos valores neles inseridos são modificados pela função que as formas adquirem nesta conjuntura.

Concordamos com Costa (2009, p. 56) para dizer que os geossímbolos religiosos são resultantes da relação entre os sujeitos e o sagrado. Pois ele afirma que

\footnotetext{
Na tentativa de conjugar elementos geossimbólicos dentro de uma contextualidade de um espaço sagrado, [...] que o homem se exprime sob formas simbólicas que se relacionam no espaço, sendo as formas e os objetos de culto eivados de uma aura de elevado valor moral.
}

Ao entender que as formas simbólicas espaciais contemplam nossa discussão, elucidamos a ideia central de interpretar o espaço sagrado representado pela IURD-TCF.

As formas simbólicas espaciais derivam do entendimento concebido pelas formas simbólicas. Para compreender a primeira precisamos, de antemão, entender a segunda. Por meio do conceito de formas simbólicas há uma reflexão direcionada a uma compreensão e aplicação das formas simbólicas espaciais, aqui baseadas nas ideias estudadas por Corrêa (2007).

Corrêa $(2007 ; 2009 ; 2012)$ procura investigar a discussão sobre a forma simbólica para tratar de diversos assuntos pertinentes à Geografia no que concerne a monumentos públicos, política, espaço geográfico. Entre seus textos, ele projeta seu entendimento sobre formas simbólicas em dois autores. Um deles é Stuart Hall (1997) em seu texto The work of representation, no qual se aborda as representações por meio da ação cultural. Contudo, ele também se embasa em Ernst Cassirer (2001), principalmente em seu trabalho A filosofia das Formas simbólicas, volume I, sobre a linguagem. Como ele utiliza estes autores em textos 
distintos, consideramos relevante analisar a ideia destes para a definição de formas simbólicas para posteriormente se chegar as formas simbólicas espaciais de Corrêa $(2007 ; 2012)$.

Corrêa afirma a forma espacial como uma representação, a partir de Hall (1997). Ele coloca que "As formas simbólicas são representações da realidade, resultantes do complexo processo pelo qual os significados são produzidos e comunicados entre pessoas de um mesmo grupo cultural” (CORRÊA, 2007, p. 7). Representações da realidade porque para Hall (1997, p. 28) “A representação é a produção de sentido através da linguagem.” (Tradução nossa). A realidade se objetiva por meio de significados constituídos na comunicação entre o grupo.

Essa comunicação produtora de sentidos ocorre por meio de uma relação entre significantes e significados. Os significantes são as formas e os significados os conceitos (CORRÊA, op.cit). Para conceituação dos objetos, precisamos visualizar e perceber as formas, a partir do momento em que as assimilamos, nossa mente busca dar-lhes significados. Assim, é a assimilação dos significantes (formas) que orientam os significados (conceitos), ou seja, as formas captadas pelo grupo são interpretadas para exprimir um significado que é repassado a outros do grupo pela linguagem.

Contudo, este processo não é simples, pois envolve dois sistemas de representação: um que está interno ao sujeito, o mapa conceitual e outro social que é a linguagem (HALL, op. cit). Temos "Em primeiro lugar, então, o significado depende do sistema de conceitos e imagens formados em nossos pensamentos que podem estar a favor ou 'representam' o mundo, o que nos permite referir-se a coisas tanto dentro como fora de nossas cabeças." (HALL, op. cit. p. 17, tradução nossa). Ou seja, a partir do que já temos mentalizado dos objetos vistos e seu respectivo significado.

O segundo corresponde à linguagem. Segundo o autor aqui analisado,

Nosso mapa conceitual comum deve ser traduzido juntamente com a linguagem, para que possamos correlacionar nossos conceitos e ideias com algumas palavras escritas, faladas, sons ou imagens visuais. O termo geral que usamos para palavras, sons ou imagens que carregam significados é signo. Estes signos mostram ou representam os conceitos e as relações conceituais entre eles e o que carregamos em nossas cabeças e, juntos, compõem os sistemas de significados da nossa cultura. (HALL, op. cit., p. 18, grifo do autor, tradução nossa).

Portanto, é a junção desses dois sistemas de representação que formam os significados daquilo que vemos ou percebemos, isto é, as formas. Logo, para este autor, notamos que o processo de significação é obtido pela relação entre o sujeito, interpretante, e o signo, objeto interpretado. 
Da mesma forma, Corrêa $(2007,2012)$ entende que as formas simbólicas são resultantes do processo de significação. Esse processo oferece uma função às formas, compondo a tríade processo, função e significado (Corrêa, 2009). Assim, as formas simbólicas são elementos de um sistema de representação. Aqui é outro ponto que Corrêa utiliza o pensamento de Hall, pois é uma aplicação da abordagem construtivista da representação. Segundo Hall (1997, p. 25),

\begin{abstract}
A terceira abordagem reconhece esse caráter público e social da linguagem. Ela reconhece que nem coisas em si nem os usuários individuais da linguagem podem decidir o significado na linguagem. O que quero dizer: nós construímos o significado, utilizando sistemas de representação - conceitos e signos." (Tradução nossa).
\end{abstract}

As funções adquiridas pelas formas, como no caso da IURD-TCF estão eivadas de significados para àqueles que o veem e/ou frequentam. A partir das formas eles dão significado as suas ações e convicções. No caso em questão, os fiéis interpretam o templo como a "casa de Deus", um lugar sagrado, onde a habitação divina fortalece a vida de quem se faz presente e participante dos rituais.

Corrêa (2012, p. 135) complementa que "se as formas simbólicas refletem os significados estabelecidos, elas também criam significados”. As formas simbólicas são duais em seu sentido: exprimem os conceitos do grupo cultural e também criam conceitos mediante as relações entre os sujeitos e as formas, no pensamento de Berque (1998), são marcas e matrizes de significados.

Ainda trilhando as ideias de Hall (1997), Corrêa (2007, p. 8) assinala: "De acordo com a corrente construtivista, as formas simbólicas são marcadas pela instabilidade de significados, pela polivocalidade." Esta é caracterizada por Hall (op.cit) por um mesmo processo ou fenômeno que pode ter interpretações diferentes, gerando significados distintos. Disto concluímos que as formas simbólicas derivam das relações sociais culturais, mas não necessariamente regradas, pois podem divergir a outras culturas distintas.

Portanto, podemos inferir que Corrêa $(2007 ; 2012)$ entende as formas simbólicas como um sistema de representação apoiado em uma abordagem construtivista da representação. Assim, as formas resultam da relação entre forma e conceito, formando signos, nos quais comunicam os grupos de uma mesma cultura.

O outro componente do entendimento de Corrêa (2009) afirmado em seu texto Processo, Forma e Significado sobre formas simbólicas partem de Cassirer (2001). Ele diz 
que para o espaço "se torne plenamente inteligível, é necessário introduzir os significados construídos e reconstruídos a seu respeito pelos diversos grupos sociais." (CORREA, op. cit, p. 4). Introduzir significados, portanto é essencial para realização espacial.

Deste modo, a relação entre o homem e a terra (DARDEL, 2015) é possível porque os homens interpretam a realidade concreta por meio de uma simbolização. Consoante ao pensamento de Cassirer (1994, p. 47),

\begin{abstract}
O homem descobriu, por assim dizer, um novo método para adaptar-se ao seu ambiente. Entre o sistema receptor e efetuador, que são encontrados em todas as espécies animais, observamos no homem um terceiro elo que podemos descrever como o sistema simbólico. Essa nova aquisição transforma o conjunto da vida humana. (grifos do autor).
\end{abstract}

Conforme acima, o homem é um ser simbólico. Logo, a realidade se constitui por meio dos símbolos criados pela vida humana ao experienciar os fatos. No entanto, para o autor citado, a realidade é objetivada pelo sistema simbólico (PEREIRA, 2014). Este sistema simbólico faz com que o homem não somente entenda a realidade em que vive, mas também crie uma forma de vivenciar o mundo. O sistema simbólico é para Cassirer (op. cit., p. 51) um dos "traços mais característicos da vida humana.". Assim, também influencia na cultura.

Seguindo esta lógica, as formas simbólicas são responsáveis pela objetivação do mundo. De igual modo "o real se constitui como unidade e pluralidade, como multiplicidade das configurações que, entretanto, afinal são unificadas através de uma unidade de significação." (CASSIRER, 2001, p. 64). Ou seja, somos sujeitos simbólicos e o que apreendemos são símbolos que nos direcionam a uma realidade.

Igualmente, o homem tem suas experiências e as transforma em símbolos. Em outras palavras "As formas simbólicas tendem a resignificar lugares específicos e conectá-los a projetos de sentido mais amplo." (OLIVEIRA e SOUZA, 2010, p. 4). Por conseguinte, a espacialidade é uma relação simbólica, pois resulta da experiência que o sujeito tem com o lugar e sua capacidade intelectual de inventar seu mundo simbólico (PEREIRA, 2014).

Portanto, o espaço é "um conjunto de funções ideais que se complementam e determinam mutuamente para formar um resultado unificado.” (CASSIRER, 2001, p. 54). Este resultado unificado é vivido pelos sujeitos em suas relações sociais, sendo a religião uma forma de simbolização presente no espaço. As formas simbólicas são associadas às formas concretas, dando sentido conforme aqueles que as vivem.

Podemos então dizer que 
Parece-nos claro que as formas se tornam simbólicas pelo depósito de significados que lhes são atribuídos; sendo o seu estudo, geográfico ou de outra natureza, passível de análises individuais e coletivas, isso porque um dado objeto pode instigar a proeminência de significações das mais variadas, diferença esta produto de um processo cultural subjetivo. (OLIVEIRA e SOUZA, 2010, p. 4, grifo dos autores).

Consequentemente, as formas concretas, são assimiladas de diferentes maneiras porque lhes são atribuídas diferentes significações, conforme o grupo que as vivenciam, modelam e propagam em sua vida social. Por exemplo, temos a forma concreta da IURD-TCF e variadas possibilidades de significações, conforme o grupo que a vivencia no cotidiano. $\mathrm{O}$ templo não tem o mesmo significado se compararmos um fiel da igreja com um ambulante que vende em frente ao espaço religioso, assim como a religião defendida pela mesma instituição diferenciam de significado para esses dois tipos de pessoas. A variedade de significados perpassa pela condição de sermos animais simbólicos (CASSIRER, 2001).

Podemos agora, compreender as formas simbólicas espaciais, pois é uma geografização das formas simbólicas estudadas por Hall (1997) e Cassirer (2001). Corrêa afirma categoricamente que "As formas simbólicas tornam-se espaciais quando estão diretamente vinculadas ao espaço, constituindo-se em fixos e fluxos, isto é, localizações e itinerários, que são atributos primários da espacialidade." (CORRÊA, 2012, p. 137). Portanto, as formas simbólicas espaciais se constituem de formas concretas (fixos), caso dos templos religiosos, como também de formas não-concretas (fluxos), caso de procissões religiosas. Ambos estão associados a significados simbólicos.

As formas simbólicas espaciais são interpretações das formas simbólicas existentes relacionadas à vivência dos sujeitos no espaço. O que nos permite dizer ser a relação entre o homem e o espaço derivada de uma experiência sentida e percebida, capaz de fazê-lo atribuir significados que o identificam naquele espaço. As formas simbólicas espaciais são arranjos cuja simbologia perceptiva do sujeito o direciona a dar um significado identitário, ou seja, a formação de geossímbolos.

Temos uma duplicidade desta formação que realça a vivência entre sujeitos e objetos, como coparticipantes da composição da paisagem, ou seja, "as formas simbólicas podem incorporar os atributos já conferidos aos lugares e itinerários, como estes podem, por outro lado, beneficiar-se ou não da presença de formas simbólicas.” (CORRÊA, 2007, p. 9). 
Se tomarmos uma forma simbólica espacial de razão religiosa, percebemos que o sagrado é um componente no significado geossimbólico do lugar. Ou como afirma (SOUZA, 2013, p. 3)

\begin{abstract}
A manifestação do poder do sagrado no espaço realiza-se por meio de formas simbólicas diversas. Imagens representativas dessas formas aparecem em procissões, romarias, peregrinações, visitas religiosas, templos, santuários, entre outros. [...]. As formas e funções devem ser entendidas por intermédio de seus significados; os significados que os homens criam, sustentam e representam.
\end{abstract}

A IURD-TCF é um representante dessa manifestação do sagrado, pois assume em suas formas um significado que potencia a função no qual ela assume. Os significados expressos pelas formas simbólicas espaciais, como o próprio templo, conduzem aos sujeitos percepções que direcionam a um comportamento distinto, uma vez que ele se sente na presença divina.

Além disso, a IURD-TCF detém um poder identitário cujos fiéis acolhem uma necessidade de frequência ao lugar para confirmar e fortalecer essa relação. Em seu cotidiano, ele não se identifica apenas como membro, mas procura constante conexão com o templo, como uma orientação espacial, seu centro no mundo. Ele se afirma como "filho de Deus" e "abençoado por Deus" na medida em que sua constância ao templo se torna frequente e duradoura. Parar de frequentar o templo significa estar "afastado", ou seja, perdendo sua identidade de "filho" e membro da família divina, além de lhe faltar o centro, orientando-se pelo espaço profano.

O espaço profano é também representado por meio de formas simbólicas espaciais, cujos significados são percebidos pelos fiéis como distintos das formas sagradas. Ele também está inserido no espaço sagrado da IURD-TCF, como símbolo do divino sobre o mundano. O profano prepara ao sagrado. O simbolismo se manifesta em um jogo de significados onde sagrado e profano não se repelem, mas se diferenciam (ROSENDAHL, 1996). A conjuntura urbana de Fortaleza ressalta as formas simbólicas espaciais e a paisagem religiosa manifestada pela IURD-TCF.

Os geossímbolos presentes remontam a um cenário captado pelos sujeitos que percebem ali a presença do sagrado. A identidade assumida pelos frequentadores do templo se fortalece e os direciona a um modo de vida que represente o discurso simbólico do lugar. 
Consignamos que as formas simbólicas espaciais são resultantes de uma relação simbólico-religiosa, nos quais o sujeito é o elemento essencial. É a partir dele que essas relações se simbolizam.

\begin{abstract}
As transformações das formas simbólicas culturais em formas simbólicas espaciais, quando temos o santuário como símbolo relevante ao e do turismo religioso, por exemplo, nos levam a crer que existe uma fenomenologia simbólico-religiosa do espaço sagrado, que merece ser analisada pelas percepções das pessoas que vivenciam este espaço. (OLIVEIRA e SOUZA, 2010, p. 19).
\end{abstract}

O espaço geográfico possui não somente as formas e funções, mas identidades formadas a partir da vivência e da experiência humana, percebida e interpretada pela mediação do corpo com as formas. As formas são extensões das ações humanas, a partir do que elas percebem e se situam no espaço.

\title{
Resultados e discussão
}

Compreendemos o espaço sagrado como uma relação simbólica mediada pelas formas simbólicas espaciais e geossímbolos que interagem com os sujeitos por meio da experiência. As formas simbólicas espaciais são elementos condicionantes de uma dimensão do sagrado, de tal forma que este se torna possível pela percepção da paisagem e elementos geossimbólicos presentes.

A IURD-TCF é uma forma simbólica espacial, cujos elementos fazem parte da interpretação simbólica dos sujeitos que vivem este lugar. Essa interpretação ocorre por meio de formas simbólicas presentes na paisagem, captadas por meio da experiência que por sua vez, é assimilada pelos sujeitos por geossímbolos assumindo significados voltados ao sagrado, revestindo a religiosidade praticada de uma realidade convergente entre o humano e o divino.

Este pensamento converge à compreensão de Dardel (2015), quando fala de geograficidade. A vivência do mundo é "uma geograficidade do homem como modo de existência e de seu destino." (DARDEL, 2015, p. 1-2, grifo do autor). É uma descoberta do mundo envolvido, cujos elementos são desvendados pela percepção dos objetos.

Porquanto o mundo para Dardel é o mundo da existência. Besse (2015, p. 114) explica que o espaço geográfico para Dardel "é o mundo da existência, um mundo que agrupa certamente as dimensões do conhecimento, mas também, e sobretudo, aquelas da 
ação e da afetividade.”. O corpo interage com o mundo, fazendo parte dele, vivendo-o, buscando a descoberta constante do espaço geográfico.

Podemos inferir que a IURD-TCF é um espaço vivido pela experiência corporal dos fiéis, de modo que a percepção comum dentre eles promove o entendimento coletivo do templo como um geossímbolo. O corpo percebe e o sujeito interage com o mundo a sua volta, no qual estabelece símbolos para compreender e criar sua realidade.

O templo é parte desse mundo e lócus de uma realidade intrínseca, permitindo aos fiéis compreenderem o mundo no qual vivem. O geossímbolo atua no sentido de lhes dar uma identidade, percebida real para cada um e juntos formando uma cultura que tem no sagrado sua representação máxima da realidade.

Tratando-se da IURD-TCF, as formas simbólicas espaciais direcionam a um espaço sagrado, cujo corpo é o elemento convergente entre o ser e o mundo. Juntos eles compreendem o transcendental envolvente na relação das formas do templo (sagradas) com as formas fora do templo (profanas). Profanas em sentido de preparação ao sagrado, pois o sagrado direciona o profano e o profano destaca o sagrado, pois aquele é amorfo (ELIADE, 1979). As formas simbólicas espaciais remetem a uma paisagem sagrada, percebida pelo corpo através de geossímbolos. Estes são identificados e construídos pela espacialidade em uma paisagem residente do sagrado.

A partir das intencionalidades humanas de compreender o mundo, há uma busca incessante de explicar a realidade. Desse modo, a vivência espacial passa por uma construção do mundo, pela corporeidade.

A IURD-TCF é uma maneira de materializar uma realidade perceptiva e as atividades, nela praticada, endossam a interpretação dos fiéis ao perceberem ali o sagrado. Para os fiéis, a igreja realiza a vivência de um lugar onde Deus está presente e sua atuação e participação é importante para se direcionar no cotidiano. É um porto seguro, cujas necessidades espirituais e materiais são atendidos. É um lugar que lhes confere uma identidade, pois na igreja eles reafirmam a aliança de "filhos de Deus", diferenciando-os das outras pessoas que vivem o caos comercial do centro urbano.

Tomando por parte dos organizadores, a IURD-TCF é uma agente de serviços simbólicos, atuante na perpetuação de uma realidade expressa por símbolos materiais (objetos usados nos cultos que firmam a ação de Deus e dos fiéis nas trocas simbólicas) e não-materiais (discurso dos pastores, fluxo das pessoas como prática de fé, campanhas 
realizadas pelos fiéis, associações entre membros ${ }^{4}$, testemunhos e rituais), conduzindo a uma experiência espacial diferente da proporcionada pelo espaço mundano. $\mathrm{O}$ encontro dessas duas posturas, a do fiel e a dos organizadores permitem uma troca simbólica (BOURDIEU, 2007) cujos agentes assumem duas extremidades da relação religiosa: a dos detentores do saber religioso ou capital simbólico e os frequentadores do templo, sendo estes assumidos de uma carência espiritual que só podem ser sanadas mediante a frequência regular e observação das ordenanças promovidas pelos líderes.

Tomando por base o entendimento de Bourdieu (2007), podemos afirmar que a IURD-TCF é uma instituição reprodutora de bens simbólicos, dos quais fiéis são desprovidos de capital simbólico, em que é oferecido no templo através do corpo de sacerdotes (bispos e pastores) no concernente a uma "teologia erigida em dogma cuja validade e perpetuação ele [corpo de sacerdotes] garante" (BOURDIEU, 2007, p. 38). Os fiéis participam dessa legitimação por meio da presença ao templo, percebendo os símbolos existentes e a partir disso, validando as práticas ensinadas. A troca existente entre eles se apresenta em dois polos extremos: "o auto-consumo religioso, de um lado, $e$ a monopolização completa da produção religiosa por especialistas, de outro lado." (BOURDIEU, op. cit. p. 40, grifos do autor). Portanto, os frequentadores da IURD-TCF, corporalmente perceptivos, são legitimadores dos bens simbólicos oferecidos pelos líderes representantes da instituição, nesse caso a maioria dos bens simbólicos são espacializados por meio dos geossímbolos.

O corpo, como portador da ponte entre ser e espaço, é o mediador do sagrado, cabendo a este a função de perceber os símbolos e ligar os objetos a significados condizentes com a proposta discursiva dos pastores e identificar no espaço sagrado o elo transcendental entre homem e Deus. Temos o corpo como um elemento geossimbolizante, pois é ele que transmite o percebido, cuja significação dada pelo sujeito se forma. O sagrado é então fruto do percebido espacialmente, ou seja, o corpo nos revela um espaço (LIMA, 2010), onde o sagrado é significado por meio das formas simbólicas espaciais existentes.

Diante disto, a IURD-TCF é uma realidade perceptiva aos seus frequentadores. Isso se afirma pelo fato de que "enfatizar a experiência do corpo como campo criador de sentidos, isto porque a percepção não é uma representação mentalista, mas um acontecimento da corporeidade e, como tal, da existência.” (NÓBREGA, 2008, p. 142). O

\footnotetext{
${ }^{4}$ São grupos de jovens, grupo de obreiros, grupo de senhores, entre outros.
} 
frequentador se orienta no espaço por meio da igreja, pois ele se vê perto ou longe de Deus na medida em que está perto ou longe do templo.

\section{Considerações Finais}

Portanto, destacamos alguns apontamentos sobre a interpretação do espaço sagrado representado pela IURD-TCF. O sagrado é vivido por meio das formas simbólicas espaciais, isso ocorre intermediado por ritos e construções simbólicas feitas a partir da vivencia dos frequentadores do templo ou de quem o observa. $\mathrm{O}$ sagrado se manifesta espacialmente porque é o elemento perceptivo da relação fiel e templo.

Para os objetos percebidos criam-se símbolos. Estes são provenientes de uma convenção cultural da justaposição dos objetos no espaço. A percepção dos símbolos ocorre por meio da experiência, sendo esta espacial, perceptiva e corporal. Os símbolos se manifestam no espaço por meio de formas visíveis e das relações cotidianas, ou seja, o símbolo é uma construção espacial. Sendo assim, as formas simbólicas espaciais são provenientes da interpretação simbólica da paisagem.

Esta paisagem se molda por meio de geossímbolos, que são fixos e fluxos ao assumirem uma dimensão simbólica que fortalece a identidade do grupo. O sujeito vivencia a paisagem pelas interações simbólicas que se manifestam espacialmente.

As formas simbólicas espaciais são interpretações das formas simbólicas que são vivenciadas no espaço e a IURD-TCF torna-se exemplo desta forma simbólica espacial.

\section{Referências bibliográficas}

BESSE, Jean-Marc. "Geografia e existência a partir da obra de Eric Dardel”. In: DARDEL, Eric. O homem e a terra. São Paulo: Perspectiva, 2012, p. 111-139.

BOURDIEU, Pierre. A economia das trocas simbólicas. 6. ed. São Paulo: Perspectiva, 2007.

CASSIRER, Ernst. Ensaio sobre o homem: uma introdução a uma filosofia da cultura humana. São Paulo: Martins Fontes, 1994.

Fontes, 2001.

A Filosofia das Formas Simbólicas I: A linguagem. São Paulo: Martins

CORRÊA, Roberto Lobato. "Formas simbólicas e espaço: algumas considerações". Geographia, Niterói, vol. 9. n. 17, p. 07-18, 2007.

"Forma, processo e significado: uma breve consideração". Revista do

Instituto histórico e geográfico do Rio Grande do Sul, Porto Alegre, 6 p., 2009. 
"Denis Cosgrove - a paisagem e as imagens". Espaço e Cultura. Rio de Janeiro: UERJ, n. 29. p. 07-21, jan/jun, 2011.

. "Espaço e simbolismo". In: CASTRO, I. E.; GOMES, P. C. C.; CORRÊA, R.

L. (orgs.). In: Olhares geográficos: modos de ver e viver o espaço. Rio de Janeiro: Bertrand Brasil, 2012, p. 133-154.

COSTA, Otávio José Lemos. "Memória e paisagem: em busca do simbólico dos lugares”. In: Espaço e Cultura. Rio de Janeiro: Eduerj, edição comemorativa, mai. 2013.

"Sertões de canindé: uma interpretação geossimbólica da paisagem". In: Espaço e Cultura. Rio de Janeiro: Eduerj. n. 26, dez., 2009.

ELIADE, Mircea. O sagrado e o profano: a essência das religiões. Coleção vida e cultura. Lisboa: Livros do Brasil, 1979.

O mito do eterno retorno: arquétipos e repetição. Lisboa: Edições 70, 1985.

HALL, Stuart. Representations: Cultural Representations and Signifying Pratices. Londres: Sage Publications, 1997.

LENCIONI, Sandra. Região e Geografia. São Paulo: Edusp, 2003.

LIMA, Elias Lopes de. "Do corpo ao espaço: Contribuições da obra de Maurice MerleauPonty à análise geográfica”. Geographia, Niterói, ano 9, n. 18, fev., 2010.

MERLEAU-PONTY, Maurice. Fenomenologia da Percepção. 4. ed. São Paulo: Martins Fontes, 2011.

MESLIN, Michel. A experiência humana do divino: fundamentos de uma antropologia religiosa. Petrópolis: Vozes, 1992.

NÓBREGA, Terezinha Petrúcia da. "Corpo, percepção e conhecimento em Merleau-Ponty". Estudos de Psicologia. Natal. n. 13 (2), p. 141-148, 2008.

OLIVEIRA, Christian Dennys Monteiro de; SOUZA, José Arilson Xavier de. "A 'geograficidade' das formas simbólicas: o santuário de Fátima da Serra Grande em análise". Confins [Online], n. 9, 2010, posto online no dia 20 Julho 2010, consultado o 29 Fevereiro 2016. URL: <http://confins.revues.org/6509> ; DOI : 10.4000/confins.6509.

PEREIRA, Clevisson Junior. Geografia da Religião e a teoria do espaço sagrado: a construção de uma categoria de análise e o desvelar de espacialidades do protestantismo batista. Curitiba, PR: CRV, 2014.

PEREIRA, Luis Andrei Gonçalves; CORREIA, Idalécia Soares; OLIVEIRA, Anelito Pereira de. "Geografia fenomenológica: espaço e percepção". Caminhos de Geografia. Uberlândia. v. 11. n. 35. p. 173-178, 2010.

ROCHA, Lurdes Bertol. "Fenomenologia, semiótica e Geografia da percepção: alternativas para analisar o espaço geográfico". Revista da casa da Geografia de Sobral. Sobral, v. 04/05, p. 67-79, 2003. 
ROSENDAHL, Zeny. Espaço e Religião: uma abordagem geográfica. Rio de Janeiro: EdUERJ, 1996.

. "O sagrado e o espaço". In: CASTRO, I. E.; GOMES, P. C. C.; CORRÊA, R. L. (orgs.) Explorações geográficas: percursos no fim do século. 3. ed. Rio de Janeiro: Bertrand Brasil, 2006, p. 119-154.

RUIZ, Castor Bartolomé. Os paradoxos do imaginário. São Leopoldo, RS: Unisinos, 2004.

SANTAELLA, Lúcia. O que é semiótica? 9. ed. São Paulo: Brasiliense, 1990.

SANTOS, Milton. Metamorfoses do espaço habitado, fundamentos teórico e metodológico da Geografia. São Paulo: Hucitec, 1988.

SOUZA, José Arilson Xavier de. "O Sagrado e a Imagem: representações no urbano". In: XIII Simpósio nacional de geografia urbana, 2013, Rio de Janeiro. Anais... XIII Simpurb 2013, 2013, p. 1-16.

Recebido em: Julho de 2017 Aceito em: Dezembro de 2017 